\title{
LINAC stereotactic radiosurgery for trigeminal neuralgia -retrospective two-institutional examination of treatment outcomes
}

\author{
Ali Rashid ${ }^{1}$, Bogdan Pintea ${ }^{2}$, Thomas M. Kinfe ${ }^{3}$, Gunnar Surber ${ }^{4}$, Klaus Hamm ${ }^{4}$ and Jan P. Boström ${ }^{1,5^{*}}$
}

\begin{abstract}
Background: In this pooled 2-center series LINAC radiosurgery (SRS) has been applied as a treatment option for a subset of refractory trigeminal neuralgia (TN) patients. This study approached to retrospectively assess the efficacy and safety of LINAC SRS and to provide a brief overview addressed to the technical development from frame-based towards frameless robotic SRS.

Methods: From 2001 to $2017 n=55$ patients (pts) were treated, $n=28$ were female (51\%), mean age: 66 years (range 36-93 years); TN etiology: 37 classic TN, 15 multiple sclerosis (MS)-related TN, 2 symptomatic TN, and 1 atypical TN. Previous treatment was present in $n=35$ (63.6\%) pts. (some multiple or combined) with $n=23$ microsurgical vascular decompression and $n=17$ percutaneous retrogasserian rhizotomy. A 6 MV LINAC (4-5 mm collimators) was applied in all pts. ( $n=26$ framebased $-n=29$ frameless robotic). The dorsal root entry zone (DREZ) was targeted in $n=35$ cases and the retrogasserian target in $n=20$ pts. with a homogeneous dose for the entire study cohort ( $90 \mathrm{~Gy})$. SRS outcome was measured using the Barrow Neurological Institute (BNI) score for pain and hypaesthesia and statistically evaluated by univariate and multivariate analyzes.

Results: Mean follow-up (FU) was 30 months (2 lost FU); the total rate of post SRS BNI pain I-Illa (=painfree w or w/o medication) was 69\% (88\% for the classic TN pts), $29 \%$ (38.8\% classic TN) were classified as BNI pain I-II (=painfree w/o medication). A BNI hypaesthesia II-III was present in $9.4 \%(n=5)$ and BNI hypaesthesia IV in $n=2$. Between groups analysis demonstrated no correlation of SRS responsiveness with age, gender, MS- or not MS-associated TN, previous surgery, framebased/frameless robotic SRS. DREZ targeting significantly better suppressed TN compared to RG targeting $(p=0.01)$. Additionally, a statistical trend for a better BNI pain outcome $(p=0.07)$ along with a significant increase in BNI hypaesthesia $(p=0.01$ ) was found when using a larger partial trigeminal 70 Gy volume.

Conclusion: Our retrospective analysis support LINAC SRS as an effective and safe treatment option in TN. Frameless robotic SRS of TN is safe when using a dedicated LINAC system. A target definition closer to the brainstem and tendencially a larger target volume were associated with a better outcome for pain.
\end{abstract}

Keywords: Radiosurgery, Linear accelerator, Trigeminal neuralgia, Outcome

\footnotetext{
* Correspondence: Jan.Bostroem@mediclin.de

'Department of Radiosurgery and Stereotactic Radiotherapy, MediClin Robert

Janker Clinic and MediClin MVZ Bonn, Villenstrasse 8, 53129 Bonn, Germany

${ }^{5}$ Department of Neurosurgery, University of Bonn Medical Center,

Sigmund-Freud-Str. 25, 53105 Bonn, Germany

Full list of author information is available at the end of the article
}

(c) The Author(s). 2018 Open Access This article is distributed under the terms of the Creative Commons Attribution 4.0 International License (http://creativecommons.org/licenses/by/4.0/), which permits unrestricted use, distribution, and

reproduction in any medium, provided you give appropriate credit to the original author(s) and the source, provide a link to the Creative Commons license, and indicate if changes were made. The Creative Commons Public Domain Dedication waiver (http://creativecommons.org/publicdomain/zero/1.0/) applies to the data made available in this article, unless otherwise stated. 


\section{Background}

Trigeminal neuralgia (TN) represents a chronic, debilitating pain condition of the trigeminal nerve and corresponding branches with an incidence of around 12 per 100.000 , disproportionately affecting elderly and female patients [1]. According to the International Classification of Headache Disorders (The International Headache Society (IHS) Criteria, 3rd edition 2014) two subtypes are distinguished. The first, the classic form of TN (with no apparent cause other than neurovascular compression) is characterized by sudden shocks of severe facial pain lasting from a fraction of a second to $120 \mathrm{~s}$ in the distribution of the facial divisions of the trigeminal nerve often precipitated by innocuous stimuli to the affected side of the face. The second subtype, the non classic form constitute of different trigeminal neuropathies attributed to other apparent causes than a neurovascular conflict like multiple sclerosis or space occupying lesions of the cerebello-pontine angle [2].

First-line treatment in the pain management of $\mathrm{TN}$ remains pharmacotherapy (carbamazepine, gabapentin, and oxcarbazepine) [1]. In case such medications are found to be inappropriate effective and/or associated with adverse side effects, invasive approaches, namely microsurgical vascular decompression (MVD) or ablative procedures like rhizotomy may be utilized [3-5]. Surgical invasive MVD ("Jannetta" decompression) requires an open craniotomy and may be associated with surgical-related complications including facial numbness, facial palsy, CSF leaks, hearing deficits, and incisional infections. Nevertheless, previous studies indicate that MVD provides long-lasting pain relief with a responder rate of around 80\% [6-8].

Alternatively, minimal-invasive percutaneous retrogasserian rhizotomies (PRR) applying glycerol, radiofrequency, or ballon compression have been found to be act effectively in providing initial pain relief. Adverse events occurred more frequently than in MVD with the majority being sensory issues $[3,9,10]$. Of note, in a minor proportion severe sensory deficits (anaesthesia dolorosa) were recorded depending on the applied technique. However, PRR studies demonstrated limited sustained TN pain suppression $[9,11]$.

Non-invasive stereotactic radiosurgery (SRS) has been reported to be a viable treatment option for TN since firstly introduced by Leksell [12]. SRS represents a non-invasive and safe alternative to minimal-invasive PRR or invasive, surgical MVD after failure of pharmacological and behavioural pain interventions [13, 14].

A rising number of clinical data has been published with an appropriate observation period with respect to Gamma Knife $^{\circledast}$ (GK) SRS for the treatment of TN [15-17]. In a large-scale review including $8 \mathrm{GK}$ series with $1215 \mathrm{TN}$ patients, Sheehan et al. observed a success rate of $>75 \%$ and a pain free rate of $50 \%$ along with a complication rate of $13 \%$ and a TN recurrence rate of $20 \%$ assessed over
20 months post GK SRS [18]. However, linear accelerator (LINAC) and robotic-assisted SRS has been increasingly applied recently for TN treatment [19-24]. Varela-Lema et al. reviewed 11 LINAC cohort studies, of which 3 were conducted prospectively, enrolling data of 549 patients. Overall, a comparable success rate of $75-95 \%$ with a $1 \mathrm{y}$ recurrence rate of $5-29 \%$, but a more variable rate of mild-to-moderate adverse events (mainly hypaesthesia) occurring in 7.5-52\% of LINAC SRS treated patients was noted [25]. Hence, systematic multicenter-based studies addressed to TN responsiveness and possible associations with dose-response interaction on target volume, target point, age, gender, adverse events, and TN origin using LINAC-based SRS have to address remaining clinically relevant open questions.

We here report on a retrospective assay of a pooled bi-centric LINAC SRS study of TN treatment covering an observation period of 15 years and assessed TN outcome, adverse events, and TN origin (classic versus non-classic). We compare the treatment results for the two most used SRS targets, the dorsal root entry zone (DREZ) and the retrogasserian (RG) target. We have additionally determined the 70 Gy volume (almost spherical), which seems empirically the minimal effective dose, and evaluated volumetrically the proportion of the trigeminal nerve within this 70 Gy volume. We have correlated these volumes with outcome as regards the therapy success as well as the side effect profile. In addition, we briefly describe the technical development from frame-based to frameless robot-assisted and image-controlled SRS with an identical LINAC irradiation system.

\section{Methods}

\section{Study cohort}

This is a two-centre retrospective study done at the "CyberKnife-Centrum Mitteldeutschland" in Erfurt, Germany and at the "MediClin Robert Janker Klinik" in Bonn, Germany. From 2001 through 2017, 55 patients (28 female, mean age 66 years, range 36 to 93 years) with clinically diagnosed $\mathrm{TN}$ were treated at our institutions and listed in a prospective clinical database (see Table 1). For all patients informed consent was obtained in accordance with the tenets of the Declaration of Helsinki, because of the retrospective nature of the study no special approval by the Ethics Committee was necessary.

The TN was classified in accordance with the international classification of headache disorders of the international headache society [2]. $N=37$ (67.3\%) patients (pts) suffered the classic (=type 1) form, the rest were pts. with non classic (=type 2 ) trigeminal neuropathies attributed to other apparent causes than a neurovascular conflict like multiple sclerosis (MS, 15 pts./27.3\%) or space 
Table 1 Descriptive statistics

\begin{tabular}{|c|c|c|c|c|c|c|c|c|c|c|c|c|c|c|}
\hline No & Sex & Age & $\begin{array}{l}\text { TN } \\
\text { etiology }\end{array}$ & $\begin{array}{l}\text { Carbamazepin } \\
\text { mono/combined } \\
=1 \text {, other }=0\end{array}$ & Pretreatment & Side & $\begin{array}{l}\text { Target } \\
\text { RG / } \\
\text { DREZ }\end{array}$ & Collimation & $\begin{array}{l}\text { Localisation } \\
\text { framebased / } \\
\text { robotic }\end{array}$ & $\begin{array}{l}\text { Dose } \\
\text { (Gy) }\end{array}$ & $\begin{array}{l}70 \text { Gy } \\
\text { TN vol. } \\
\text { (cc) }\end{array}$ & $\begin{array}{l}\text { FU } \\
\text { (mo) }\end{array}$ & $\begin{array}{l}\text { BNI } \\
\text { hypaesthesia }\end{array}$ & $\begin{array}{l}\text { BNI pain } \\
\text { last FU }\end{array}$ \\
\hline 1 & f & 81 & classic & 1 & MVD & right & DREZ & $4 \mathrm{~mm}$ Cones & framebased & 90 & - & 116 & I & । \\
\hline 2 & $\mathrm{~m}$ & 78 & classic & 1 & $2 \times M V D$ & left & DREZ & $4 \mathrm{~mm}$ Cones & framebased & 90 & 0,013 & 62 & ॥ & । \\
\hline 3 & $\mathrm{~m}$ & 74 & classic & 1 & MVD & left & DREZ & $4 \mathrm{~mm}$ Cones & framebased & 90 & 0,014 & 28 & । & Illa \\
\hline 4 & $\mathrm{~m}$ & 44 & classic & 1 & MVD & right & DREZ & $4 \mathrm{~mm}$ Cones & framebased & 90 & 0,012 & 200 & $\|$ & । \\
\hline 5 & $\mathrm{~m}$ & 93 & classic & 1 & MVD & right & DREZ & $4 \mathrm{~mm}$ Cones & framebased & 90 & 0,011 & 9 & । & । \\
\hline 6 & $f$ & 83 & classic & 1 & MVD, PRR & left & DREZ & $4 \mathrm{~mm}$ Cones & framebased & 90 & 0,015 & 14 & । & IIla \\
\hline 7 & $\mathrm{~m}$ & 82 & classic & 0 & - & left & DREZ & $4 \mathrm{~mm}$ Cones & framebased & 90 & 0,009 & 83 & $\|-1\|$ & IIla \\
\hline 8 & $\mathrm{~m}$ & 70 & classic & 0 & MVD, PRR & right & DREZ & $4 \mathrm{~mm}$ Cones & framebased & 90 & 0,02 & 107 & $\|-\| \|$ & IIla \\
\hline 9 & f & 63 & classic & 1 & - & left & DREZ & $4 \mathrm{~mm}$ Cones & framebased & 90 & 0,007 & 104 & I & IIla \\
\hline 10 & f & 72 & classic & 1 & MVD & right & DREZ & $4 \mathrm{~mm}$ Cones & framebased & 90 & 0,009 & 102 & 1 & IIla \\
\hline 11 & $\mathrm{~m}$ & 75 & classic & 1 & - & left & DREZ & $4 \mathrm{~mm}$ Cones & framebased & 90 & 0,006 & - & - & - \\
\hline 12 & $\mathrm{~m}$ & 51 & MS & 0 & MVD & left & DREZ & $4 \mathrm{~mm}$ Cones & framebased & 90 & 0,03 & 24 & ॥ & IIIb \\
\hline 13 & f & 36 & MS & 1 & PRR & left & DREZ & $4 \mathrm{~mm}$ Cones & framebased & 90 & 0,013 & 90 & I & I \\
\hline 14 & $\mathrm{~m}$ & 76 & classic & 1 & - & right & DREZ & $4 \mathrm{~mm}$ Cones & framebased & 90 & 0,012 & 2 & I & Illa \\
\hline 15 & $f$ & 55 & classic & 0 & MVD & left & DREZ & $4 \mathrm{~mm}$ Cones & framebased & 90 & 0,014 & 14 & I & IIla \\
\hline 16 & $f$ & 63 & MS & 1 & $4 \times P R R$ & left & DREZ & $4 \mathrm{~mm}$ Cones & framebased & 90 & 0,006 & 67 & I & IIla \\
\hline 17 & $\mathrm{~m}$ & 78 & classic & 1 & - & right & DREZ & $4 \mathrm{~mm}$ Cones & framebased & 90 & 0,048 & 2 & I & IIla \\
\hline 18 & $\mathrm{~m}$ & 70 & classic & 0 & MVD, PRR & left & DREZ & $4 \mathrm{~mm}$ Cones & framebased & 90 & 0,021 & 10 & 1 & IIla \\
\hline 19 & $f$ & 69 & MS & 1 & - & right & DREZ & $4 \mathrm{~mm}$ Cones & framebased & 90 & 0,016 & 27 & । & Illa \\
\hline 20 & $f$ & 74 & classic & 1 & $\mathrm{MVD}, 2 \times \mathrm{PRR}$ & right & DREZ & $4 \mathrm{~mm}$ Cones & framebased & 90 & 0,032 & 22 & I & IIla \\
\hline 21 & $f$ & 74 & classic & 0 & RT & right & DREZ & $4 \mathrm{~mm}$ Cones & framebased & 90 & 0,02 & 19 & I & । \\
\hline 22 & $f$ & 58 & MS & 0 & - & left & DREZ & $4 \mathrm{~mm}$ Cones & framebased & 90 & 0,039 & 34 & $\|-\mid\|$ & । \\
\hline 23 & $\mathrm{~m}$ & 47 & MS & 1 & - & left & DREZ & $4 \mathrm{~mm}$ Cones & framebased & 90 & 0,033 & - & - & - \\
\hline 24 & $f$ & 46 & MS & 1 & - & left & DREZ & $4 \mathrm{~mm}$ Cones & framebased & 90 & 0,044 & 22 & । & IIla \\
\hline 25 & $f$ & 67 & classic & 0 & - & right & DREZ & $4 \mathrm{~mm}$ Cones & framebased & 90 & 0,021 & 22 & $\|-\mid\|$ & । \\
\hline 26 & $f$ & 76 & classic & 0 & PRR & left & DREZ & $4 \mathrm{~mm}$ Cones & framebased & 90 & 0,04 & 20 & $\|-I\|$ & । \\
\hline 27 & $\mathrm{~m}$ & 51 & sympt. & 1 & PRR & left & RG & $4 \mathrm{~mm} \mu \mathrm{MLC}$ & robotic & 90 & 0,013 & 69 & $\|$ & V \\
\hline 28 & m & 71 & classic & 0 & MVD, $2 \times$ PRR & right & DREZ & $5 \mathrm{~mm}$ Cones & robotic & 90 & 0,04 & 7 & I & । \\
\hline 29 & $f$ & 60 & classic & 1 & PRR & right & RG & $4 \mathrm{~mm} \mu \mathrm{MLC}$ & robotic & 90 & 0,023 & 2 & $\|$ & $\|$ \\
\hline 30 & $\mathrm{~m}$ & 64 & classic & 1 & MVD & right & RG & $4 \mathrm{~mm} \mu \mathrm{MLC}$ & robotic & 90 & 0,033 & 12 & । & V \\
\hline 31 & $\mathrm{~m}$ & 75 & classic & 1 & MVD & left & RG & $4 \mathrm{~mm} \mu \mathrm{MLC}$ & robotic & 90 & 0,048 & 22 & ॥ & IIla \\
\hline 32 & f & 83 & classic & 1 & - & right & $R G$ & $4 \mathrm{~mm} \mu \mathrm{MLC}$ & robotic & 90 & 0,047 & 9 & $\|$ & IIla \\
\hline 33 & $f$ & 44 & MS & 0 & $5 \times P R R$ & right & RG & $4 \mathrm{~mm} \mu \mathrm{MLC}$ & robotic & 90 & 0,021 & 10 & । & IIla \\
\hline 34 & $f$ & 59 & MS & 0 & MVD, PRR & left & RG & $4 \mathrm{~mm} \mu \mathrm{MLC}$ & robotic & 90 & 0,03 & 8 & । & IIlb \\
\hline 35 & $f$ & 56 & MS & 0 & - & left & DREZ & $5 \mathrm{~mm}$ Cones & robotic & 90 & 0,024 & 37 & I & IIIb \\
\hline 36 & f & 80 & classic & - & - & left & DREZ & $5 \mathrm{~mm}$ Cones & robotic & 90 & 0,035 & 42 & ॥ & IIlb \\
\hline 37 & $\mathrm{~m}$ & 43 & MS & 1 & $2 \times P R R$ & right & RG & $4 \mathrm{~mm} \mu \mathrm{MLC}$ & robotic & 90 & 0,05 & 30 & I & Illb \\
\hline 38 & $f$ & 76 & classic & 0 & - & left & RG & $4 \mathrm{~mm} \mu \mathrm{MLC}$ & robotic & 90 & 0,042 & 18 & IV & । \\
\hline 39 & f & 84 & classic & 1 & PRR & left & RG & $4 \mathrm{~mm}$ Cones & robotic & 90 & 0,008 & 11 & I & IIla \\
\hline 40 & $f$ & 79 & classic & 0 & - & right & $R G$ & $4 \mathrm{~mm}$ Cones & robotic & 90 & 0,008 & 12 & I & I \\
\hline 41 & f & 51 & MS & 1 & - & right & RG & $4 \mathrm{~mm}$ Cones & robotic & 90 & 0,007 & 4 & I & V \\
\hline 42 & $\mathrm{~m}$ & 51 & MS & 1 & PRR & right & RG & $4 \mathrm{~mm}$ Cones & robotic & 90 & 0,004 & 2 & ॥ & V \\
\hline 43 & $\mathrm{~m}$ & 44 & MS & 1 & PRR & right & RG & $4 \mathrm{~mm}$ Cones & robotic & 90 & 0,004 & 6 & ॥ & Illa \\
\hline
\end{tabular}


Table 1 Descriptive statistics (Continued)

\begin{tabular}{|c|c|c|c|c|c|c|c|c|c|c|c|c|c|c|}
\hline No & Sex & Age & $\begin{array}{l}\text { TN } \\
\text { etiology }\end{array}$ & $\begin{array}{l}\text { Carbamazepin } \\
\text { mono/combined } \\
=1, \text { other }=0\end{array}$ & Pretreatment & Side & $\begin{array}{l}\text { Target } \\
\text { RG / } \\
\text { DREZ }\end{array}$ & Collimation & $\begin{array}{l}\text { Localisation } \\
\text { framebased / } \\
\text { robotic }\end{array}$ & $\begin{array}{l}\text { Dose } \\
\text { (Gy) }\end{array}$ & $\begin{array}{l}70 \text { Gy } \\
\text { TN vol. } \\
\text { (cc) }\end{array}$ & $\begin{array}{l}\mathrm{FU} \\
\text { (mo) }\end{array}$ & $\begin{array}{l}\text { BNI } \\
\text { hypaesthesia }\end{array}$ & $\begin{array}{l}\text { BNI pain } \\
\text { last FU }\end{array}$ \\
\hline 44 & m & 66 & sympt. & 0 & RT & left & RG & $4 \mathrm{~mm}$ Cones & robotic & 70 & 0,001 & 7 & I & V \\
\hline 45 & m & 69 & MS & 1 & - & right & RG & $4 \mathrm{~mm}$ Cones & robotic & 90 & 0,007 & 12 & I & V \\
\hline 46 & m & 57 & classic & 1 & $2 \times M V D, P R R$ & right & DREZ & $5 \mathrm{~mm}$ Cones & robotic & 90 & 0,042 & 17 & I & IIla \\
\hline 47 & f & 40 & classic & 1 & $2 \times M V D$ & right & DREZ & $5 \mathrm{~mm}$ Cones & robotic & 90 & 0,036 & 23 & III & V \\
\hline 48 & m & 76 & classic & 1 & $2 \times M V D$ & right & DREZ & $5 \mathrm{~mm}$ Cones & robotic & 90 & 0,034 & 18 & ॥ & IIla \\
\hline 49 & $\mathrm{~m}$ & 64 & classic & 1 & $2 \times M V D$ & right & DREZ & $5 \mathrm{~mm}$ Cones & robotic & 90 & 0,031 & 21 & I & I \\
\hline 50 & m & 78 & classic & 0 & - & left & RG & $4 \mathrm{~mm}$ Cones & robotic & 90 & 0,008 & 14 & I & IIla \\
\hline 51 & f & 73 & classic & 1 & - & left & RG & $4 \mathrm{~mm}$ Cones & robotic & 90 & 0,007 & 5 & ॥ & $\|$ \\
\hline 52 & f & 78 & atyp. & 1 & MVD (left) & right & RG & $4 \mathrm{~mm}$ Cones & robotic & 90 & 0,008 & 8 & IV & IV \\
\hline 53 & f & 74 & classic & 1 & - & right & RG & $4 \mathrm{~mm}$ Cones & robotic & 90 & 0,005 & 6 & 1 & $\|$ \\
\hline 54 & f & 81 & classic & 1 & MVD & left & DREZ & $5 \mathrm{~mm}$ Cones & robotic & 90 & 0,039 & 7 & I & IV \\
\hline 55 & $\mathrm{f}$ & 64 & classic & 1 & $2 \times M V D$ & right & DREZ & $5 \mathrm{~mm}$ Cones & robotic & 90 & 0,049 & 6 & ॥ & I \\
\hline
\end{tabular}

MS multiple sclerosis, MVD microsurgical vascular decompression, $P R R$ percutaneous retrogasserian rhizotomy, $R T$ radiotherapy, $D R E Z$ dorsal root entry zone, $R G$ retrogasserian, BNI Barrow Neurological Institute, FU follow-up, $m$ male, $f$ female, mo month, vol. volume, sympt. symptomatic, atyp. atypical

occupying lesions (2 symptomatic cases/3.6\%), and other (1 atypical TN/1.8\%).

Mean age of patients with non classic TN (> MS related) was significantly lower (55 vs. 73 years, $p=0.0001$ ).

From these 55 patients 35 pts. (63.6\%) were surgically pretreated regarding the TN, 23 pts. (41.8\%) were pretreated with MVD and 17 pts. (30.9\%) with PRR.

All pts. had already been adjusted by medication with (Ox-) Carbamazepin (37/55), Pregabalin (17/55), Gabapentin (13/55), opiate/opioide analgetics (14/55) and/or others.

\section{Stereotactic radiation treatment and FU-assessment}

The majority of pts. $(n=46)$ underwent single-session stereotactic radiosurgery (SRS) using the Novalis ${ }^{\circ}$-system (Brainlab ${ }^{\oplus}$ A, München, Germany), the rest of the patients $(n=9)$ were treated with the Cyberknife ${ }^{\circ}$-system (Accuray ${ }^{\oplus}$ Inc., Sunnyvale, California, USA).

In the years 2001 to 2012 the framebased Novalis ${ }^{\bullet}$-system was used $(n=26)$, after that only frameless radiosurgery was performed, using the Novalis ${ }^{\oplus}$-system $(n=20)$ and the Cyberknife ${ }^{-}$-system $(n=9)$. The basic techniques have already been described elsewhere [21-24, 26-28].

In all cases a $6 \mathrm{MV}$ LINAC with $4-5 \mathrm{~mm}$ collimators (cones/micro multi-leaf collimator $(\mu M L C)$ ) was used, SRS was $n=26$ framebased and $n=29$ frameless robotic.

Patients undergoing first-time SRS treatments typically received a peak dose (dose to $100 \%$ isodose point) of $90-$ 95 Gy delivered in 9 to 16 non coplanar arcs (Novalis ${ }^{\oplus}$-system, Brainlab ${ }^{\star}$ AG, München, Germany) or approx. 160 beams (Cyberknife ${ }^{\bullet}$-system, Accuray Inc., Sunnivale, USA). In all but one cases the prescription dose was
90 Gy. This single patient was pretreated elsewhere with conventional radiotherapy because of cancer.

The 20\% isodose line at the limit of the brainstem surface was used as constraint for the brainstem.

The stereotactic CT was used for the bony information, in particular for depicting the transition of the trigeminal nerve from intracranial space to the cavum Meckeli. The 3 D T1 sequence with contrast enhancement served for the contouring of the brainstem. For the identification of the trigeminal nerve we routinely used fast gradient echo steady-state sequences (Fig. 2).

In $n=35$ cases the target point was the dorsal root entry zone (DREZ) (Fig. 1) and in $n=20$ cases retrogasserian (RG) (Fig. 2). After intervention, the patients received a strict follow-up (FU) care (after 2 months, 6 months, yearly) consisting of a clinical and radiological investigation with MRI (minimum T1 with gadolinium and steady state sequences). The FU MRI results were merged and volumetrically assessed using the Brainlab $^{\oplus}$ iPlan $^{\odot}$ RT Image version 4.1.2 or the BrainSCAN ${ }^{\bullet}$ version 5.31 (both Brainlab $^{\odot}$ AG, München, Germany), for examples see Figs. 1 and 2 .

Treatment outcome (see Table 1) was measured using the Barrow Neurological Institute (BNI) score for pain and hypaesthesia:

Barrow Neurological Institute (BNI) score

BNI pain intensity score

I No trigeminal pain, no medication

II Occasional pain, not requiring medication

Illa No pain, continued medication 


\begin{tabular}{ll} 
(Continued) & \\
IIIb & Persistent pain, controlled with medication \\
IV & Some pain, not adequately controlled with medication \\
BNI facial numbness score \\
I & No facial numbness \\
II & Mild facial numbness, not bothersome \\
III & Facial numbness, somewhat bothersome \\
IV & Facial numbness, very bothersome \\
\hline
\end{tabular}

Toxicities were evaluated with Common Toxicity Criteria (CTC) version 3.0.

\section{Volumetric assessment of the trigeminal nerve and $70 \mathrm{~Gy}$} volume determination

Using the Brainlab ${ }^{\circ}$ iPlan $^{\circ}$ RT Dose version 4.5.5 (Brainlab $^{\circ}$ AG, München, Germany) retrospective assessing of treatment volumes as the 70 Gy volume and trigeminal volume inside the 70 Gy volume was done for all patients in Bonn. In order to calculate the trigeminal volume inside the 70 Gy volume, the 70 Gy volume was subtracted from the trigeminal volume and the difference between original trigeminal volume and subtracted trigeminal volume was calculated. The Brainlab $^{\circ}$ BrainSCAN version 5.31 software in Erfurt had been used for all treated patients from 2001 to 2012. This version of software was able to show trigeminal volume inside 70 Gy volume directly at the dose-volume histograms. From 2012 all treatments in Erfurt had been planned with Cyberknife ${ }^{\circ}$ software MultiPlan version 4.6 (Accuray Inc., Sunnivale, USA), which also calculates trigeminal volume inside the $70 \mathrm{~Gy}$ volume directly.

\section{Statistical methods}

Statistical univariate and multivariate analysis was performed using $\mathrm{IBM}^{\circ}$ SPSS Statistic $20^{\circ}\left(\mathrm{IBM}^{\circ}\right.$, Armonk, NY, USA) software to determine which patient and treatment related factors influenced the outcome (BNI score for pain and hypaesthesia). Factors evaluated included patient's age and sex, TN form (classic = type 1 , non classic = type 2 : MS-related, symptomatic, atypical), FU time, fixation (framebased/frameless), collimation $(4 \mathrm{~mm} / 5 \mathrm{~mm}$ cones/ $\mu \mathrm{MLC}$ ), target point (DREZ/RG), and trigeminal 70 Gy volume, respectively. For numerical data t-tests and for categorical data Fisher's exact test and Pearson $x^{2}$ Test were used. Statistical significance was assessed as $p<0.05$.

\section{Results}

Two patients did not have sufficient FU; for the patients with an available FU $(n=53)$, the mean FU was 30.7 months, range 2-200 months (Table 1).

The overall rate of treatment success, defined as BNI pain I-IIIa (=painfree $\mathrm{w}$ or w/o medication) was $69 \%$, the overall rate for painfree w/o medication $(=$ BNI I-II) was $29 \%$.

In the patients with classic TN (type 1), the BNI I-IIIa rate was $91.6 \%$ at first $\mathrm{FU}(33 / 36,1$ lost FU) and $88.8 \%$

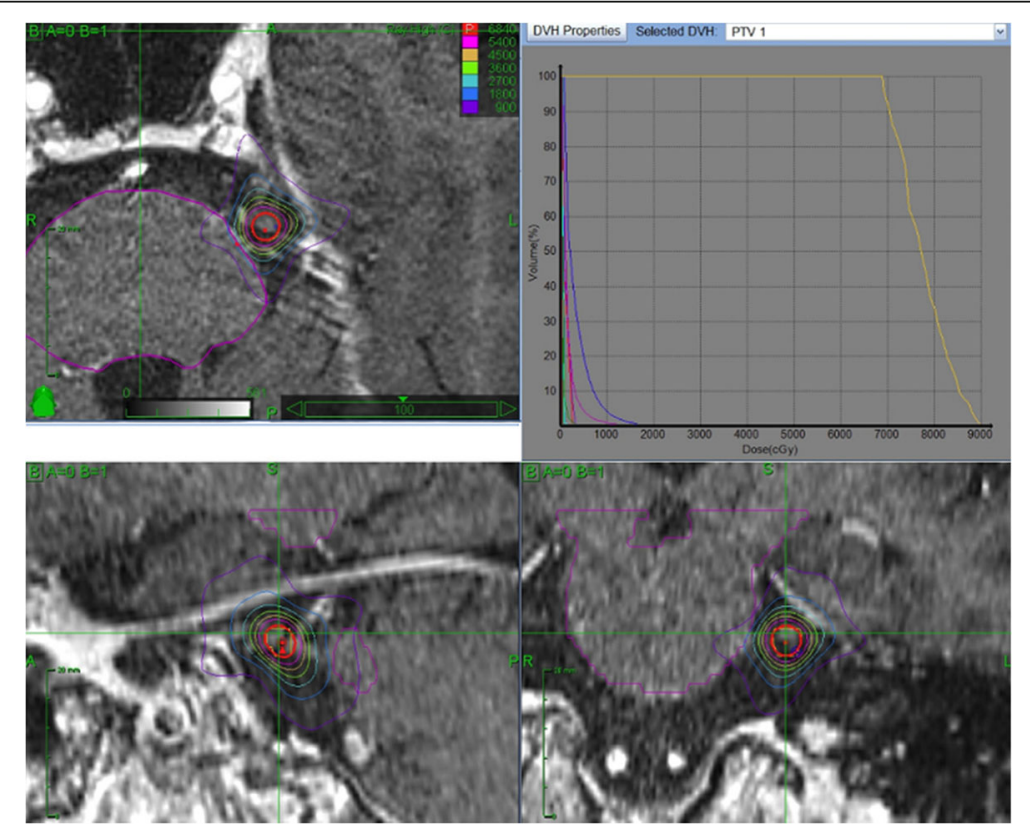

Fig. 1 Dorsal root entry zone (DREZ) target. Typical plan with DREZ target (red circle), isodoses and dose-volume histograms (DVH) for trigeminal nerve (yellow line) and for different organs at risk (OAR) (blue line = brainstem) 

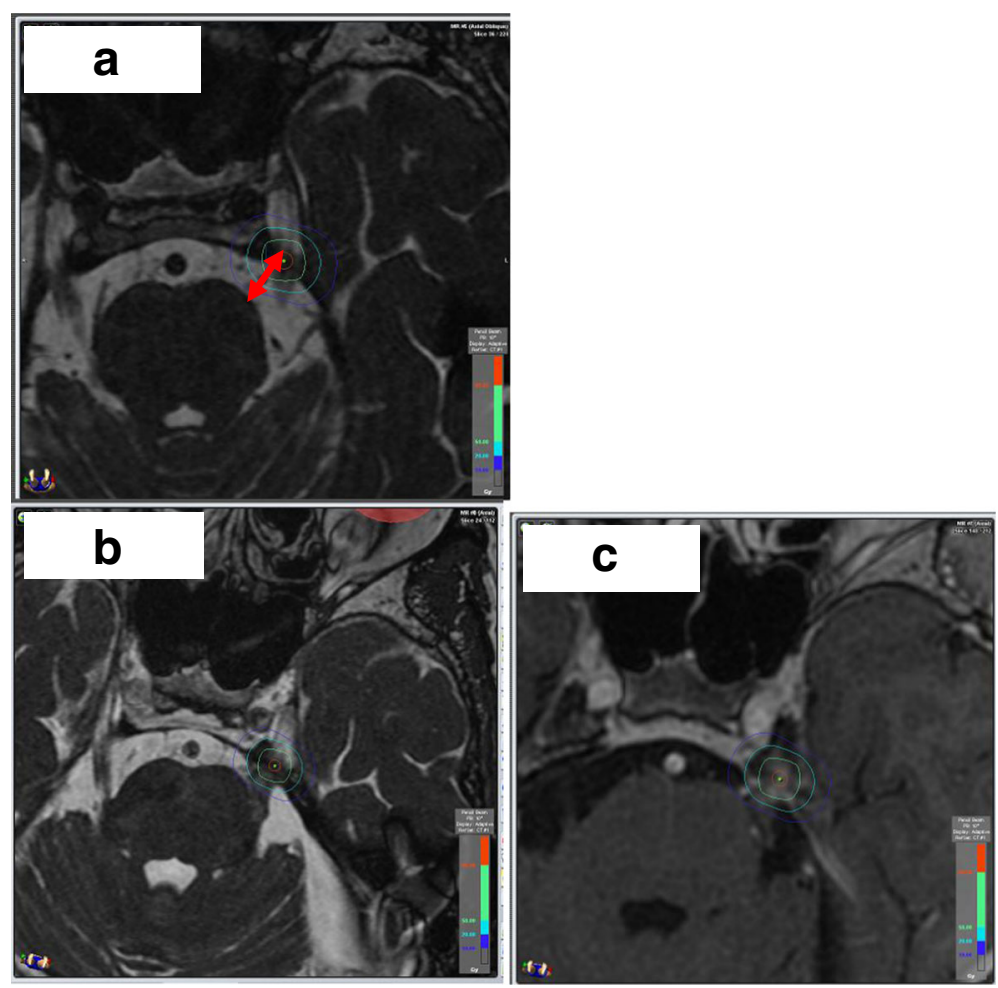

Fig. 2 a-c Retrogasserian (RG) target post Janetta decompression. Different situation pre (a) and post (b) Janetta decompression with narrowed space in the prepontine cistern (red arrow). Typical small dot-shaped contrast enhancement 2 months after radiosurgery (c)

at last available FU (32/36, 1 lost FU) and the BNI I-II rate was $47.2 \%$ at first $\mathrm{FU}(17 / 36,1$ lost FU) and $38.8 \%$ (14/36, 1 lost FU) at last available FU.

The mean BNI score was not significantly different between the classic (type 1) and the non classic (type 2)
TN (2.2 vs. 2.8) (Figs. 3 and 4). In the patients with MS-related TN, the BNI I-IIIa rate at first FU was $64.3 \%$ (9/14, 1 lost FU) and 50.0\% (7/14, 1 lost FU) at last available $\mathrm{FU}$, significantly lower than the rate of classic $\mathrm{TN}, p=0.03$ and $p=0.003$ respectively. The BNI I-II rate

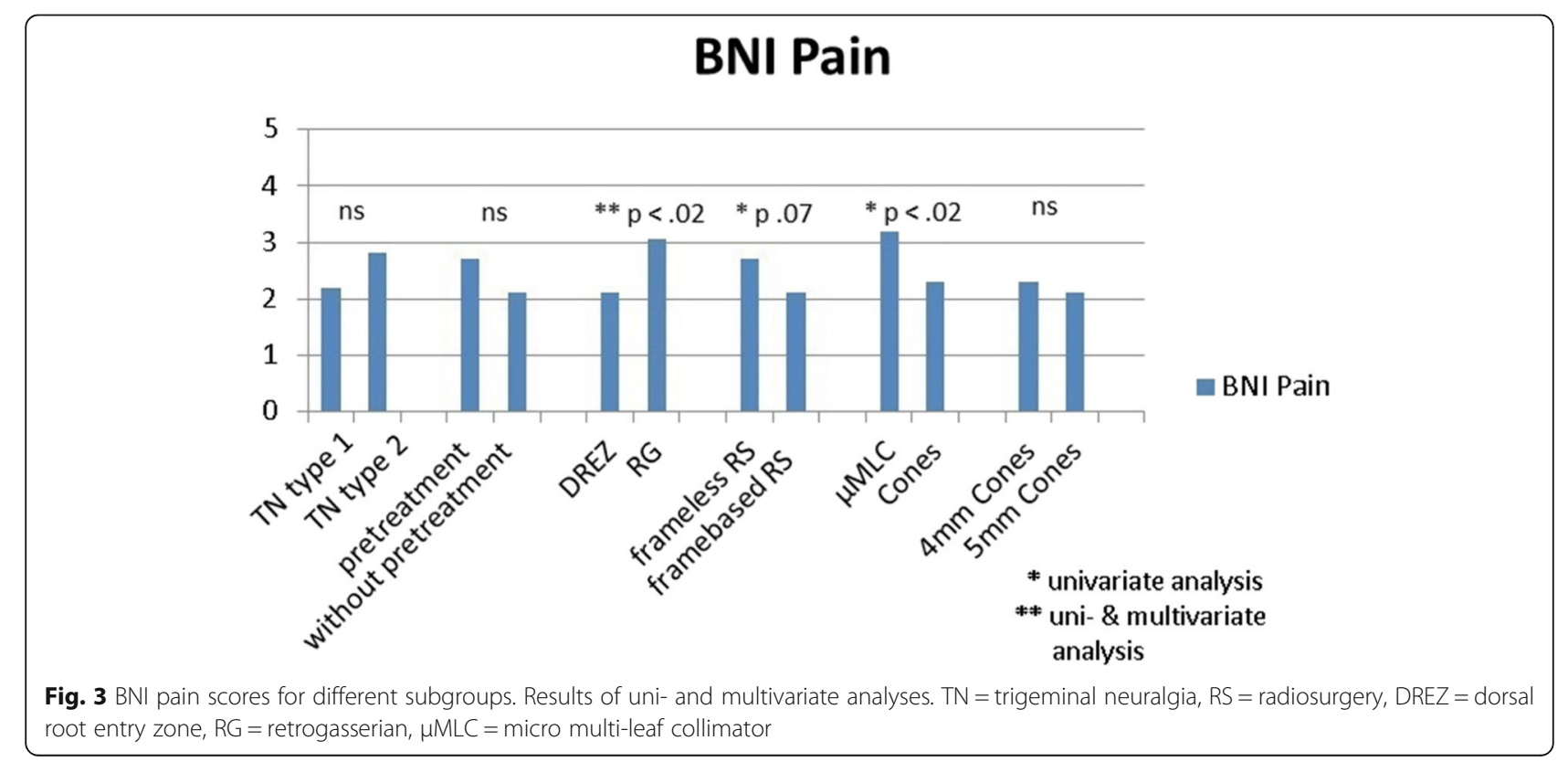




\section{BNI Hypaesthesia}

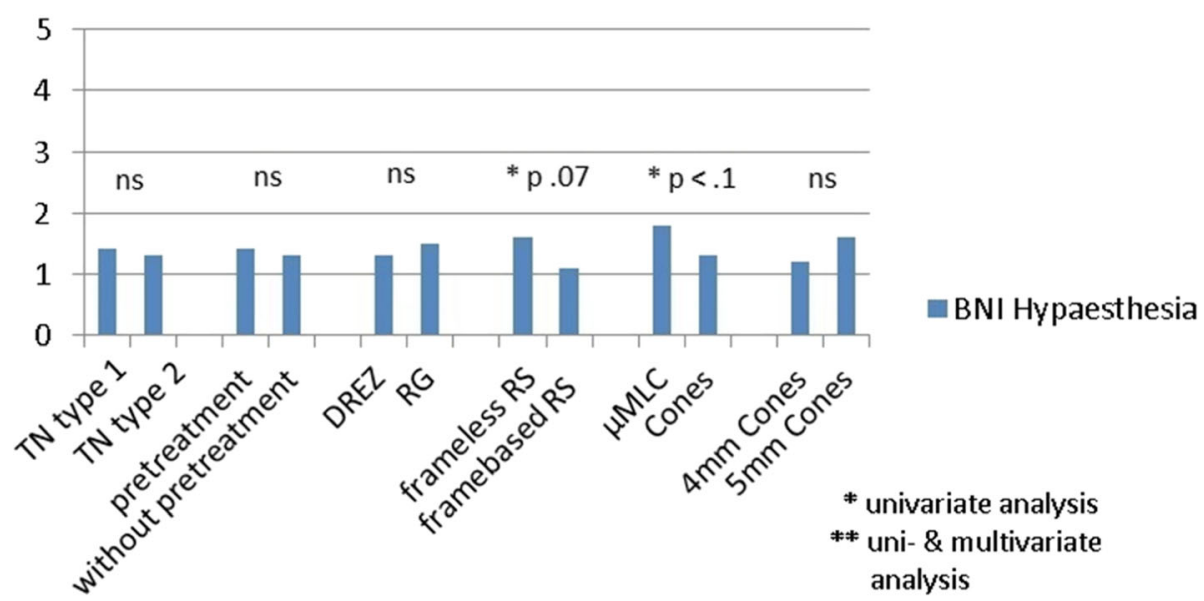

Fig. 4 BNI hypaesthesia scores for different subgroups. Results of univariate analyses. $T N=$ trigeminal neuralgia, RS = radiosurgery, DREZ = dorsal root entry zone, $\mathrm{RG}=$ retrogasserian, $\mu \mathrm{MLC}=$ micro multi-leaf collimator

was $21.4 \%(3 / 14,1$ lost FU) at first FU and 14.3\% (2/14, 1 lost FU) at last available FU, not significantly different to the classic TN. The rate for symptomatic and atypical TN was statistically not meaningful evaluable, since this group was represented by 3 patients, only.

We found only a weak statistical tendency of a better outcome in case of framebased SRS vs. frameless robotic SRS for BNI pain (framebased: 2.1 vs. frameless: 2.7, $p=$ 0.07 ) and BNI hypaesthesia at first FU (framebased: 1.1 vs. frameless: 1.6, $p=0.07$ ) (Figs. 3 and 4).

No statistical difference between $4 \mathrm{~mm}$ and $5 \mathrm{~mm}$ cones but a statistical tendency for a better outcome was found when using cones instead of $\mu \mathrm{MLC}$. BNI pain score: cones: 2.2 vs. $\mu \mathrm{MLC}$ : $3.2 ; p=0.056$; BNI hypaesthesia score: cones: 1.3 vs. $\mu$ MLC: $1.8 ; p=0.098$ (Figs. 3 and 4).

Further on, we found a significant difference of the BNI pain score at 1st FU depending to the target point (Figs. 3 and 4), the DREZ target proofed to be better than the RG target (2.1 vs. 3.1, $p=0.01$ ), but there were no significant differences for the BNI I-IIIa and BNI I-II rates at the first follow up.

The overall rate of new hypaesthesia BNI II-III was 9.4\% ( $n=5,2$ lost FU) and only in $n=1$ a new BNI hypaesthesia IV was noted. This female patient with a classic TN had at

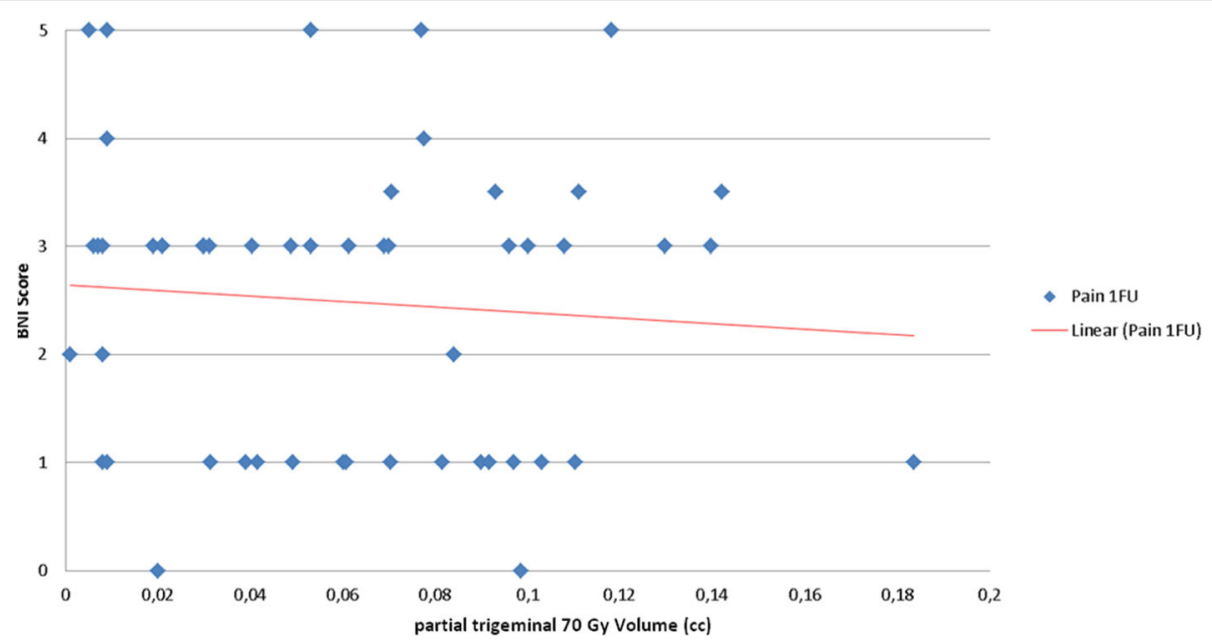

Fig. 5 Relation of BNI pain at 1. FU and partial trigeminal 70 Gy volume. BNI=Barrow Neurological Institute, FU=follow-up 
the same time a BNI pain outcome score of I (no trigeminal pain attacks). In one patient the hypaesthesia BNI IV was pre-existing.

In patients with classical $\mathrm{TN}$, the new hypaesthesia $\mathrm{BNI}$ II-III rate was $13.8 \%$ (5/36, 1 lost FU), in patients with MS-related TN the BNI II-III hypaesthesia rate was 7.1\% (4/14, 1 lost FU), this was not significantly different. Again, the rate for symptomatic and atypical TN was statistically not meaningful evaluable, since this group was represented by 3 patients, only.

Concerning to possible (CTC) toxicities no patient with a decreased corneal sensation (dry eye syndrome) was found. None of the patients reported jaw (masseter) weakness or anaesthesia dolorosa. There were no cases of morbidity in areas other than the trigeminal nerve, such as any brainstem injury.

\section{Multivariate analysis}

The univariate statistical results were further analyzed with multivariate analysis. The multivariate analysis of potential influencing factors showed no significant difference in terms of outcome (BNI pain and BNI hypaesthesia scores) for age, gender, MS or not MS-related, w or w/o pretreatment, framebased or frameless SRS.

The target point remains the only significant variable in the multivariate analysis for the BNI pain score at 1st FU, the DREZ target proofed to be better than the RG target. No persistent significant variable could be found in the multivariate analysis regarding the BNI hypaesthesia score (Figs. 3 and 4).

\section{Influence of the partial trigeminal volume inside the $70 \mathrm{~Gy}$ isodose sphere}

The percentage of the volume of the trigeminal nerve inside the approximately spherical 70 Gy volume (=partial trigeminal volume) ranged from 10 to 50\% (mean: $36.1 \%$, median: 34.6\%). In absolute terms this means that the trigeminal volume irradiated with a minimal dose of 70 Gy ranged from 0.001 to $0.05 \mathrm{cc}$ (mean: $0.020 \mathrm{cc}$, median: $0.018 \mathrm{cc}$ ), when excluding the one case with a prescription dose of $70 \mathrm{~Gy}$, it ranged from 0.004 to 0.05 (mean: $0.022 \mathrm{cc}$, median: $0.020 \mathrm{cc}$ ).

When dichotomizing to a partial trigeminal $\mathrm{TN}$ volume of $40 \%$ and when comparing the cases with $\leq 40 \%$ partial volume vs. $>40 \%$ partial volume a statistical significance for a higher grade of BNI hypaesthesia $(p=0.01)$ and a statistical tendency of a lower grade of BNI pain at 1st FU $(p=0.07)$ were observed, meaning a larger partial trigeminal volume correlated weakly with a better outcome for the BNI pain score (Fig. 5), but at the same time correlated significantly with a higher score of BNI hypaesthesia.

\section{Discussion}

An acceptable effectiveness (overall BNI I-IIIa success rate of $69 \%$ and of $88 \%$ in the classic TN subgroup) with low side effects $(<11 \%)$ was found in our 2 center series of LINAC SRS for TN with a total of 55 patients including pretreated and MS-related TN subtypes. In addition, our series showed that a SRS target closer to the brainstem (DREZ target) and tendencially also a larger target volume (more precisely: a larger partial trigeminal 70 Gy volume) were associated with an improved responsiveness without necessarily provoking more relevant side effects. No significant relationship was found between age, gender, presence of MS diagnosis, surgical or ablative pre-treatment and SRS outcome.

Radiosurgery is no curative therapy, but a valuable treatment option for TN [29]. It is to be noted that in Europe and in Germany the option SRS is used comparatively rarely in TN. Although this is also seen worldwide, the frequency of its application is once again reduced by a factor of 5-10 in Europe [30]. The literature on SRS in TN is traditionally dominated by GK series [31], the largest series of patients with the longest follow-up can be found there [16, 32].

One of the most experienced single GK centers in Pittsburgh reported a success rate of $85 \%$ (complete pain free $70 \%$ ) in 220 patients with a mean FU of 2 years [15]. Other GK series with a longer FU reported a decrease of pain relief of $>25 \%$ after 5 years [24, 31, 33, 34].

Only few studies $[3,9,33]$ have compared different methods of non-drug treatment of $\mathrm{TN}$, including a recent study that compared the standard (micro-)neurosurgical therapy (microsurgical vascular decompression = MVD or Janetta procedure) with GK SRS [34]. This prospective study reported a initial success (painfree $=$ BNI I) rate of $95 \%$ vs. $75 \%$, respectively, and a persistent effect after 5 years of $65 \%$ vs. $50 \%$, respectively, and after 10 years of 45 vs. 35\%, respectively [34]. Although the Janetta decompression had an initial higher success rate than SRS, both therapies showed a considerable loss of success (of 40-50\%) after 10 years.

The reported patient numbers in series using LINAC SRS for the treatment of TN are comparatively fewer [19-24, 28, 35-38], consequentially fewer numbers of patients can be reviewed in total, but there are also some smaller prospective LINAC studies (for review see [25]). Synoptically, the reported success rates are very similar to the published rates of GK therapy. However, the rates of treatment-related side effects (hypaesthesia) appear to be significantly more variable $(7.5-52 \%)$ [25]. This may be due to the fact that the treatment modalities of LINAC SRS are more variable because different LINAC systems with different skull fixations, different monitoring during the irradiation and also different planning and dosage concepts were 
applied. Naturally, here the GK therapy has the advantage of system homogeneity. Therefore, it was rational at the start to compare different dosing and target concepts for the GK treatment $[18,39,40]$. Regarding the GK therapy as the golden standard, these concepts were essentially transferred to LINAC SRS and modified according to the LINAC system used, which did not always work satisfactorily. There are comparatively only few LINAC studies that have compared intrinsically different treatment modalities with the same LINAC system. One of the most experienced LINAC groups could prove that a dose concept with 90 Gy was more successful than a dose concept with a maximum dose of 70 Gy $[41,42]$. In our series, we therefore consistently used 90 Gy as prescribed dose in the isocenter with only one exception in a previously irradiated patient, where we used 70 Gy instead.

We consider our series as a viable contribution to the LINAC radiosurgery literature for treatment of TN. The relatively long observation period reflects one of the strengths of our study. Of importance, we have used a very homogeneous dosing concept and a similar 6 MV LINAC system with an almost identical collimation using 4-5 mm $\mu \mathrm{MLC}$ or cones over the past 15 years, so that we are able to report about a relatively homogeneous patient collective. Our series included framebased and advanced robotassisted approaches and our cohort consisted of two proportionally comparable groups of patients. In addition, we also have proportionally comparable groups with an emphasis to the classic target points, the DREZ and the RG target, so we could compare these too in terms of outcome and side effects. As the result, there was no significant difference in the multivariate analysis between framebased and frameless robotic SRS, here we found only a weak statistical tendency for a slightly better outcome (BNI pain and BNI hypaesthesia) for the framebased SRS in the univariate analysis. We found a significant difference of BNI pain (1st FU or last FU) when comparing the two used target points, the DREZ target proved to be better than the RG target.

Comparable to a study on GK SRS [43], we can here confirm that the brainstem nearer target promises a higher success rate than the more brainstem distant target. But it has to be noted that another GK study did not confirm that result [44]. Hence, both targets may be considered from our point of view. The RG target still has its justification in individual cases, as it can be very well verified, both during planning and during irradiation in case of image-guided frameless SRS, because of the closer bony relation and it provides a safe target alternative especially for individual cases with an anatomically narrow prepontine space, in particular of relevance in microsurgical pretreated cases, if through scarred displacements of the brainstem the prepontine space is reduced (Fig. 2).
With the volumetric evaluation of the partial trigeminal volume within the 70 Gy isodose, we gained an additional parameter that was statistically significant in our patient series. The $70 \mathrm{~Gy}$ isodose threshold for a sufficient effective analgesic isodose was empirically selected after literature review of both, the relevant GK literature and the LINAC literature $[18,42]$. If one postulates that the 70 Gy volume remains relatively the same because of a very similar system configuration for each patient in our series, then the individual diameter of the nerve and the individual centering of the approximately spherical 70 Gy volume will have the most influence on the percentage and absolute value of the partial trigeminal volume within this 70 Gy sphere. Our hypothesis that the volume fraction of the trigeminal nerve within this postulated minimal effective threshold may play a role for the analgetic impact of LINAC SRS has been confirmed in our series to the extent that we observed a statistical tendency of an improved outcome for BNI pain in case of a larger partial 70 Gy volume (when performing a dichotomy at the $40 \%$ partial 70 Gy volume). As a consequence, the planning should focus on a perfect centering and a sufficient diameter of the nerve to increase the proportion of the nerve which receives a 70 Gy minimum dose. But otherwise and with it we see also significantly more BNI hypaesthesia, meaning the more trigeminal tissue is captured by the $70 \mathrm{~Gy}$ isodose the better the response to pain but the more new radiogenic hypaesthesia has to be accepted, however the hypaesthesia rate in our series was still relatively low at about $11 \%$.

We did not look specifically at the length of the nerve inside the treatment volume, but of course the length of the nerve and the volume of the nerve correlate with each other. Flickinger et al. using GK SRS examined the influence of the nerve length in the treatment volume and found a similar connection, viz. the longer the irradiated nerve length was, the more side effects in form of sensory disturbances occurred. However and in contrast to our findings, no difference was found regarding pain outcome [39].

The possible higher rate of hypaesthesia has to be communicated to the patients and ultimately, this should in our opinion be discussed with the patients, whether they accept a higher rate of hypaesthesia as a calculated risk to achieve maybe a better pain relief in LINAC SRS for TN.

\section{Limitations}

The low patient case number is surely a limiting factor. Our mean follow up is not sufficient for long-term results. We prospectively collected our patient series and treatment data, but partly evaluated retrospectively our outcome data. The parameter 70 Gy volume has only been found empirically and may only be valid for our 
series and cannot be generalized. This applies to all our results, but we hope that our carefully collected data will be nevertheless a significant contribution to future meta-analyzes on LINAC SRS in trigeminal neuralgia.

\section{Conclusions}

LINAC SRS is no curative therapy in TN, but it is a valid treatment option for TN because of its acceptable effectiveness even in pretreated and MS-related cases. A target definition closer to the brainstem side and tendencially also a larger target volume inside the $70 \mathrm{~Gy}$ isodose line were correlated with a better pain outcome in our series. Frameless robotic SRS can be performed in the same quality as framebased SRS when using a dedicated LINAC system. Large-scale controlled trials comparing different approaches are required in order to evidently confirm the potential value of LINAC SRS and to promote its wider application.

\section{Abbreviations \\ BNI: Barrow Neurological Institute; DREZ: Dorsal root entry zone; DVH: Dose- volume histogram; FU: Follow-up; GK: Gamma Knife; LINAC: Linear accelerator; MS: Multiple sclerosis; MVD: Microsurgical vascular decompression; OAR: Organs at risk; PRR: Percutaneous retrogasserian rhizotomy; RG: Retrogasserian; SRS: Stereotactic radiosurgery; TN: Trigeminal neuralgia; $\mu \mathrm{MLC}$ : Micro multi-leaf collimator}

\section{Availability of data and materials}

The datasets used and/or analysed during the current study are available from the corresponding author on reasonable request.

\section{Authors' contributions}

All of the authors have been involved in drafting this paper and have read and approved the final manuscript. JPB conceived the idea of the paper, AR collected the data and performed with JPB the relevant literature research. $A R$, JPB and TMK wrote the paper. BP performed the statistical analysis. $\mathrm{KH}$, GS and JPB performed the radiosurgical procedures.

\section{Ethics approval and consent to participate}

For all patients informed consent was obtained in accordance with the tenets of the Declaration of Helsinki. Because of the retrospective nature of the study no special approval by the local Ethics Committee was necessary. This manuscript does not report on or involve the use of any animal or human data or tissue.

\section{Consent for publication}

Not applicable, because this manuscript does not contain any individual persons data.

\section{Competing interests}

The authors declare that they have no competing interests.

\section{Publisher's Note}

Springer Nature remains neutral with regard to jurisdictional claims in published maps and institutional affiliations.

\footnotetext{
Author details

'Department of Radiosurgery and Stereotactic Radiotherapy, MediClin Robert Janker Clinic and MediClin MVZ Bonn, Villenstrasse 8, 53129 Bonn, Germany. ${ }^{2}$ Department of Neurosurgery, BG University Hospital Bergmannsheil, Bürkle-de-la-Camp-Platz 1, 44789 Bochum, Germany. ${ }^{3}$ Department of Psychiatry, Division of Medical Psychology, University Hospital of Bonn, Sigmund-Freud-Strasse 25, 53105 Bonn, Germany. ${ }^{4}$ CyberKnife Zentrum Mitteldeutschland, Nordhäuser Strasse 74, 99089 Erfurt, Germany.
}

${ }^{5}$ Department of Neurosurgery, University of Bonn Medical Center Sigmund-Freud-Str. 25, 53105 Bonn, Germany.

Received: 10 July 2018 Accepted: 16 August 2018

Published online: 22 August 2018

\section{References}

1. Zakrzewska J, Linskey ME. Trigeminal Neuralgia. Clinical Evidence. 2014;10: 1207.

2. Headache Classification Committee of the International Headache Society (IHS). The international classification of headache disorders, 3rd edition. Cephalalgia. 2018:38:1-211.

3. Fraioli B, Esposito V, Guidetti B, Cruccu G, Manfredi M. Treatment of trigeminal neuralgia by thermocoagulation, glycerolization, and percutaneous compression of the gasserian ganglion and/or retrogasserian rootlets: longterm results and therapeutic protocol. Neurosurgery. 1989;24:239-45.

4. Young RF. Glycerol rhizolysis for treatment of trigeminal neuralgia. J Neurosurg. 1988;69:39-45

5. Jannetta PJ. Arterial compression of the trigeminal nerve at the pons in patients with trigeminal neuralgia. J Neurosurg. 1967;26:159-62.

6. Barker FG 2nd, Jannetta PJ, Bissonette DJ, Larkins MV, Jho HD. The longterm outcome of microvascular decompression for trigeminal neuralgia. N Engl J Med. 1996;334:1077-83.

7. Broggi G, Ferroli P, Franzini A, Servello D, Dones I. Microvascular decompression for trigeminal neuralgia: comments on a series of 250 cases, including 10 patients with multiple sclerosis. J Neurol Neurosurg Psychiatry. 2000;68:59-64.

8. Miller JP, Acar F, Burchiel KJ. Classification of trigeminal neuralgia: clinical, therapeutic, and prognostic implications in a series of 144 patients undergoing microvascular decompression. J Neurosurg. 2009;111:1231-4.

9. Tronnier VM, Rasche D, Hamer J, Kienle AL, Kunze S. Treatment of idiopathic trigeminal neuralgia: comparison of long-term outcome after radiofrequency rhizotomy and microvascular decompression. Neurosurgery. 2001;:48:1261-7.

10. Han I, Shin D, Chang J, Kim K, Chang J, Huh R, Chung S. Effect of various surgical modalities in recurrent or persistent trigeminal neuralgia. Stereotact Funct Neurosurg. 2010;88:156-62.

11. Lunsford LD, Apfelbaum RI. Choice of surgical therapeutic modalities for treatment of trigeminal neuralgia: microvascular decompression, percutaneous retrogasserian thermal, or glycerol rhizotomy. Clin Neurosurg. 1985;32:319-33.

12. Leksell L. Stereotaxic radiosurgery in trigeminal neuralgia. Acta Chir Scand. 1971;137:311-4.

13. Kondziolka D, Perez B, Flickinger JC, Habeck M, Lunsford LD. Gamma knife radiosurgery for trigeminal neuralgia: results and expectations. Arch Neurol. 1998:55:1524-9.

14. Rogers CL, Shetter AG, Fiedler JA, Smith KA, Han PP, Speiser BL. Gamma knife radiosurgery for trigeminal neuralgia: the initial experience of the barrow neurological institute. Int J Radiat Oncol Biol Phys. 2000;47:1013-9.

15. Kondziolka D, Lunsford LD, Flickinger JC. Stereotactic radiosurgery for the treatment of trigeminal neuralgia. Clin J Pain. 2002;18:42-7.

16. Régis J, Tuleasca C, Resseguier N, Carron R, Donnet A, Yomo S, Gaudart J, Levivier $\mathrm{M}$. The very long-term outcome of radiosurgery for classical trigeminal neuralgia. Stereotact Funct Neurosurg. 2016;94:24-32.

17. Maesawa S, Salame C, Flickinger JC, Pirris S, Kondziolka D, Lunsford LD. Clinical outcomes after stereotactic radiosurgery for idiopathic trigeminal neuralgia. J Neurosurg. 2001;94:14-20.

18. Sheehan J, Pan HC, Stroila M, Steiner L. Gamma knife surgery for trigeminal neuralgia: outcomes and prognostic factors. J Neurosurg. 2005;102:434-41.

19. Gerbi BJ, Higgins PD, Cho KZH, Hall WA. LINAC-based stereotactic radiosurgery for treatment of trigeminal neuralgia. J Appl Clin Med Phys. 2004;5:80-90.

20. Richards GM, Bradley KA, Tome WA, Bentzen SM, Resnick DK, Mehta MP. Linear accelerator radiosurgery for trigeminal neuralgia. Neurosurgery. 2005; 57:1193-200.

21. Zahra H, Teh BS, Paulino AC, Yoshor D, Trask T, Baskin D, Butler EB. Stereotactic radiosurgery for trigeminal neuralgia utilizing the BrainLAB Novalis system. Technol Cancer Res Treat. 2009;8:407-12.

22. Tang $C$, Chang SD, Tseng KY, Liu MY, Ju DT. CyberKnife stereotactic radiosurgica rhizotomy for refractory trigeminal neuralgia. J Clin Neurosci. 2011;18:1449-53. 
23. Lazzara BM, Ortiz O, Bordia R, Witten MR, Haas JA, Katz AJ, Brown JA. Cyberknife radiosurgery in treating trigeminal neuralgia. J Neurointerv Surg. 2011;5:81-5.

24. Chen JC, Rahimian J, Rahimian R, Arellano A, Miller MJ, Girvigian MR. Frameless image-guided radiosurgery for initial treatment of typical trigeminal neuralgia. World Neurosurg. 2010;74:538-43.

25. Varela-Lema L, Lopez-Garcia M, Maceira-Rozas M, Munoz-Garzon V. Linear accelerator stereotactic radiosurgery for trigeminal neuralgia. Pain Physician. 2015;18:15-27.

26. Rahimian J, Chen JC, Rao AA, Girvigian MR, Miller MJ, Greathouse HE. Geometrical accuracy of the Novalis stereotactic radiosurgery system for trigeminal neuralgia. J Neurosurg. 2004;101:351-5.

27. Adler JR Jr, Bower R, Gupta G, Lim M, Efron A, Gibbs IC, Chang SD, Soltys SG. Nonisocentric radiosurgical rhizotomy for trigeminal neuralgia. Neurosurgery. 2009;64:84-90.

28. Kim DG. LINAC frameless image-guided radiosurgery for initial treatment of typical trigeminal neuralgia. World Neurosurg. 2010;74:541.

29. Lettmaier S. Radiosurgery in trigeminal neuralgia. Phys Med. 2014;30:592-5.

30. Hamilton T, Dade Lunsford L. Worldwide variance in the potential utilization of gamma knife radiosurgery. J Neurosurg. 2016;125:160-5.

31. Dhople AA, Adams JR, Maggio WW, Naqvi SA, Regine WF, Kwok Y. Longterm outcomes of gamma knife radiosurgery for classic trigeminal neuralgia: implications of treatment and critical review of the literature. Clinical article. J Neurosurg. 2009;111:351-8

32. Kondziolka D, Zorro O, Lobato-Polo J, Kano H, Flannery TJ, Flickinger JC, Lunsford LD. Gamma knife stereotactic radiosurgery for idiopathic trigeminal neuralgia. J Neurosurg. 2010;112:758-65.

33. Henson CF, Goldman HW, Rosenwasser RH, Downes MB, Bednarz G, Pequignot EC, Werner-Wasik M, Curran WJ, Andrews DW. Glycerol rhizotomy versus gamma knife radiosurgery for the treatment of trigeminal neuralgia: an analysis of patients treated at one institution. Int J Radiat Oncol Biol Phys. 2005; 63:82-90.

34. Wang DD, Raygor KP, Cage TA, Ward MM, Westcott S, Barbaro NM, Chang EF. Prospective comparison of long-term pain relief rates after first-time microvascular decompression and stereotactic radiosurgery for trigeminal neuralgia. Neurosurg. 2018;128:68-77.

35. Pokhrel D, Sood S, McClinton C, Saleh H, Badkul R, Jiang H, Stepp T, Camarata $P$, Wang F. Linac-based stereotactic radiosurgery (SRS) in the treatment of refractory trigeminal neuralgia: detailed description of SRS procedure and reported clinical outcomes. J Appl Clin Med Phys. 2017;18:136-43.

36. Sckolnik SE, Jeffrey KM, Stea B. Frameless LINAC image guided radiosurgery for primary and recurrent trigeminal neuralgia. Int J Radiat Oncol Biol Phys. 2014;90:683.

37. Karam SD, Tai A, Snider JW, Bhatia S, Bedrick EJ, Rashid A, Jay A, Kalhorn C, Nair $\mathrm{N}$, Harter KW, Collins SP, Jean W. Refractory trigeminal neuralgia treatment outcomes following Cyberknife radiosurgery. Radiat Oncol. 2014;9:257.

38. Villavicencio AT, Lim M, Burneikiene $S$, Romanelli P, Adler JR, McNeely L, Chang SD, Fariselli L, McIntyre M, Bower R, Broggi G, Thramann JJ. Cyberknife radiosurgery for trigeminal neuralgia treatment: a preliminary multicenter experience. Neurosurgery. 2008;62:647-55.

39. Flickinger JC, Pollock BE, Kondziolka D, Phuong LK, Foote RL, Stafford SL, Lunsford LD. Does increased nerve length within the treatment volume improve trigeminal neuralgia radiosurgery? A prospective double-blind, randomized study. Int J Radiat Oncol Biol Phys. 2001;51:449-54.

40. Lucas JT, Nida AM, Isom S, Marshall K, Bourland JD, Laxton AW, Tatter SB, Chan MD. Predictive nomogram for the durability of pain relief from gamma knife radiation surgery in the treatment of trigeminal neuralgia. Int J Radiat Oncol Biol Phys. 2014;89:120-6.

41. Goss BW, Frighetto L, DeSalles AA, Smith Z, Solberg T, Selch M. Linear accelerator radiosurgery using 90 gray for essential trigeminal neuralgia: results and dose volume histogram analysis. Neurosurgery. 2003;53:823-8.

42. Smith ZA, Gorgulho AA, Bezrukiy N, McArthur D, Agazaryan N, Selch MT, De Salles AA. Dedicated linear accelerator radiosurgery for trigeminal neuralgia: a single-center experience in 179 patients with varied dose prescriptions and treatment plans. Int J Radiat Oncol Biol Phys. 2011;81:225-31.

43. Matsuda S, Serizawa T, Nagano O, Ono J. Comparison of the results of 2 targeting methods in gamma knife surgery for trigeminal neuralgia. J Neurosurg. 2008;109:185-9.

44. Park SH, Hwang SK, Kang DH, Park J, Hwang JH, Sung JK. The retrogasserian zone versus dorsal root entry zone: comparison of two targeting techniques of gamma knife radiosurgery for trigeminal neuralgia. Acta Neurochir. 2010; 152:1165-70.

Ready to submit your research? Choose BMC and benefit from:

- fast, convenient online submission

- thorough peer review by experienced researchers in your field

- rapid publication on acceptance

- support for research data, including large and complex data types

- gold Open Access which fosters wider collaboration and increased citations

- maximum visibility for your research: over $100 \mathrm{M}$ website views per year

At BMC, research is always in progress.

Learn more biomedcentral.com/submissions 